\title{
Context-dependent lateralization of trunk movements in wild Asian elephants
}

\author{
Andrey Giljov ${ }^{1}$, Shermin de Silva ${ }^{2,3}$, and Karina Karenina ${ }^{1}$ \\ ${ }^{1}$ Department of Vertebrate Zoology, Saint Petersburg State University, \\ Russia, 199034, Saint Petersburg, Universitetskaya nab., 7-9; zoology.gilev@gmail.com \\ ${ }^{2}$ Elephant, Forest and Environment Conservation Trust, \\ Sri Lanka, Colombo 5, 215 A 3/7 Park Road \\ ${ }^{3}$ Smithsonian Conservation Biology Institute, USA, VA 22630, Front Royal, 1500 Remount Rd \\ Correspondence and requests for materials should be addressed to Andrey Giljov
}

\begin{abstract}
Asymmetrical trunk use in elephants represents a distinctive example of motor lateralization. Previous studies have shown that trunk movements in the elephant behaviour associated with feeding is lateralized at the individual, but not the population level. The manifestation of lateralized behaviour depends on the nature of the behaviour and is usually more pronounced in social context. Therefore, we hypothesized that population-level lateralization of trunk use in elephants is manifested in social behaviour. One-sided biases in trunk movements were assessed in wild individually-identified Asian elephants during feeding (tearing off a tuft of grass) and social interactions (trunk-to-mouth contacts and trunk-to-genitals contacts between male initiator and female recipient). In feeding, lateralization at the individual and population levels was estimated based on 50 lateral trunk uses per individual. In social interactions, only the population-level bias was assessed using a single trunk contact from each individual. For trunk movements during feeding, elephants showed robust individual preferences, but no population-level lateralization. The distribution of right- and left-trunkers in the present study did not differ significantly from that obtained in previous studies of both the same elephant population and geographically distinct population. No population-level bias in trunk movements during trunk-to-mouth contacts was revealed. In trunk-to-genitals contacts, in contrast, a population-level lateralization was found. Right-sided trunk movements prevailed in males touching females. While individual preferences for feeding, combined with the absence of one-sided population bias, is obviously a species-typical characteristic of Asian elephants, social behaviour, such as male-female socio-sexual contacts, can elicit population-level lateralization of trunk use in this species. The right-sided bias in trunk-to-genitals contacts may reflect lateralization of olfactory perception. If this is the case, the revealed lateralization indicates a right-hemispheric advantage in the processing of social information which is consistent with the general tendency in mammals.
\end{abstract}

Keywords: laterality of trunk use, functional asymmetry of the trunk, trunk contacts, free-ranging Asian elephants, motor preferences, feeding, social laterality, lateralization of unpaired organs.

\section{Introduction}

Motor lateralization, which can be defined as side biases in animals' movements, is assessed by measuring motor preferences and/or differences in motor performance (Mutha et al., 2013). Previously believed to be unique to humans, lateralized motor functions are currently considered to be a pervasive mammalian characteristic (Hook, 2004; Rogers, 2009; Rogers and Vallortigara, 2017). Lateralization of limb use has been investigated in a wide range of vertebrate species (reviewed in Ströckens et al., 2013). Vertebrates appear to show a significant variation in the degree of lateralization, ranging from species showing neither individual (i.e. 
one-sided preference of a subject) nor population (i.e. one-sided bias in a group of subjects) forelimb preferences to species highly lateralized at both individual and population levels. At least a half of all studied species have been found to have left- or right-forelimb preference at the population level (Ströckens et al., 2013). In mammalian taxa, wild black bears, Ursus americanus, for instance, have been shown to use the right forelimb more often than the left one when scavenging (Reimchen and Spoljaric, 2011). Reindeers, Rangifer tarandus, in contrast, preferentially use their left foreleg for digging feeding craters (Espmark and Kinderas, 2002).

The prevalence of lateralized forelimb use in nonhuman species raises questions about potential evolutionary advances of manual lateralization. Limited available evidence indicates that strongly lateralized individuals tend to outperform less lateralized individuals in certain tasks (Magat and Brown, 2009). For example, in wild chimpanzees the efficiency of termite fishing positively correlates with the degree of an individual's hand preference (McGrew and Marchant, 1999). Other mammals such as: cats (Lorincz and Fabre-Thorpe, 1996); bonnet macaques (Mangalam et al., 2014); and, chimpanzees (Phillips et al., 2013) have been also shown to perform better with the preferred forelimb. Thus, at least in some animals, lateralized use of the forelimb is associated with potential fitness benefits. Despite numerous studies on a variety of species, clear theoretical understanding of the neural mechanisms underlying motor lateralization is lacking. The motor cortex of each hemisphere largely controls movement of the contralateral side of the body (e.g., Hellige, 1993). In line with this, the preferred forelimb has enlarged representation in the contralateral hemisphere as compared to the non-preferred forelimb (Nudo et al., 1992). Correlations between forelimb preference and structural asymmetry in the motor cortex or the regions of the cortex outside the motor cortex have been repeatedly shown in primates (reviewed in Rogers, 2009); however, the fundamental origin of the superiority of one side/limb remains a topic of debate. The recently discussed theory argues that there is no specialization of one hemisphere in motor control, but each hemisphere is specialized for distinct and complementary aspects of control (Shabbott and Sainburg, 2008; Mutha et al., 2013). Consistent with this, the manifestation of population-level motor biases seems to depend on the nature of the motor task (Rogers, 2009).

The majority of studies on motor lateralization in animals have been focused on the use of paired limbs (Ströckens et al., 2013). Meanwhile, the movements of unpaired appendages, such as the tail, can also be lateralized as shown for primates (Laska and Tutsch, 2000; Hanbury et al., 2010), rats (Denenberg and Yutzey, 1985; Afonso et al., 1993), and dogs (Quaranta et al., 2007). A distinctive example of this type of lateralization is asymmetrical trunk use in elephants. The trunk is very flexible and sensitive organ capable for fine manipulation and used in a great variety of behaviours (Shoshani, 1998; Shoshani et al., 2006). Previous studies have examined lateralization of trunk use in elephant behaviour associated with feeding. Asian elephants, Elephas maximus, were examined both in captivity (Haakonsson and Semple, 2009) and in the wild (in Sri Lanka: Martin and Niemitz, 2003; in India: Keerthipriya et al., 2015), while a female African elephant, Loxodonta cyclotis, was observed in the zoo (Racine, 1980). In contrast to humans (Perelle \& Ehrman 1994), great apes (Meguerditchian et al., 2013), bipedal marsupials (Giljov et al., 2015), parrots (Harris, 1989), anuran amphibians (Malashichev, 2006) and many other vertebrates (Ströckens et al.,2013), elephants showed no population-level side biases in their manipulative behaviours neither with the use of the trunk nor with the use of the forelimbs (Haakonsson and Semple, 2009; Martin and Niemitz, 2003; Keerthipriya et al., 2015). However, taking into account that manifestation of motor lateralization depends on the nature of the task (Rogers, 2009), the full understanding of the lateralized trunk use in elephants cannot be gained without investigating it in different behavioural contexts.

Lateralized behaviour is known to be especially pronounced in relation to socially significant objects as compared to other types of stimuli (e.g., Forrester et al., 2014a; Karenina et al., 2013; 2017; Quaresmini et al., 2014). For example, both human children and feral horse foals prefer to keep conspecifics on their left side, but show no side bias when choosing a position relative to inanimate objects (Forrester et al., 2014a; Karenina et al., 2017). In studies of motor lateralization, social context has been suggested to incorporate different patterns of hemispheric specialization in the performance of the action as compared with non-social context (Forrester et al., 2014b). Generally, actions directed to social partners and the self tend to increase the left hand use indicating greater involvement of right hemisphere (Forrester et al. 2013; Rogers and Kaplan, 1995). Based on this concept, we suggest that social context can favour or at least modify the expression of lateralization of trunk use in elephants as compared with non-social context. Elephants use their trunks in various aspects of intraspecific interactions, for example, in tactile, chemosensory and display behaviour (e.g., Rasmussen and Schulte, 1998; Loizi et al., 2009; Yasui and Idani, 2016). Here we assessed lateralized use of the trunk during feeding and social contacts in wild Asian elephants. We aimed to investigate whether population-level lateralization is pronounced in social contacts as opposed to non-social behaviours. A secondary aim was to examine the stability of lateralization in feeding over time and its consistency across geographically distinct populations using the results of the present and previous studies. 


\section{Materials and Methods}

\section{STUDY SITES AND SUBJECTS}

Data on wild Asian elephants, Elephas maximus, were collected in Uda Walawe National Park, Sri Lanka. The park is situated in South Sri Lanka and encloses a $308-\mathrm{km}^{2}$ large area of forest, former teak tree plantations, bush vegetation, and open grassland. Most of data were collected at the valleys surrounding Uda Walawe and Mau Ara reservoirs providing yearround water as well as at several smaller seasonal natural and artificial waterbodies. These open areas provide great opportunity for daytime observations, since Uda Walawe elephants groups feed there on the short grass during the dry season (Martin and $\mathrm{Ni}$ emitz, 2003). The total population of elephants in the park is estimated to be about a thousand individuals (de Silva et al., 2011).

\section{INDIVIDUAL IDENTIFICATION}

All individuals met were photographed for subsequent photo-identification based primarily on morphology of the ears, tail, back and other body characters (de Silva et al., 2011; Vidya et al., 2014). Subjects were sexed visually and classified into four broad age classes: adults, subadults, juveniles, and calves basing on the relative height and body proportions (Arivazhagan \& Sukumar 2008; de Silva et al., 2011; Varma et al., 2012).

\section{DATA COLLECTION PROCEDURE}

The data collection for wild elephants was conducted from the research vehicle on grazing aggregations in the morning and in the late afternoon in August - September 2016. Because of everyday presence of tourist vehicles within the park, the elephants were habituated to cars, which stayed on the park roads. Under these circumstances, the research vehicle seemed not to change the behaviour of elephants significantly. Observations of elephants were conducted opportunistically when we followed groups for as long as they were visible or until necessary amount of observations were scored.

Lateral trunk movements during feeding were identified according to the direction in which the distal end of the trunk wrapped to grab and tear off a tuft of grass (Fig. 1). A trunk movement was defined as right-sided when the distal end of the trunk was laid on its left side on the ground and wrapped toward the right (clockwise around a tuft of grass). Likewise, trunk action was termed left-sided when the distal end of the trunk was laid on its right side and wrapped toward the left (anti-clockwise around a tuft of grass). To obtain discrete responses in feeding, after a single act was registered, the subsequent feeding event was taken into account only if the individual made at least one step and reached for another tuft of grass.

Lateral trunk movements during social interactions were registered when an elephant-initiator stretched the trunk, and then touched another elephant (with


Fig. 1. Left-sided trunk movement during feeding — an elephant wrapped the distal end of the trunk to the left to tear off a tuft of grass ( $\mathbf{a}$ - a general view; b - a close-up view). 

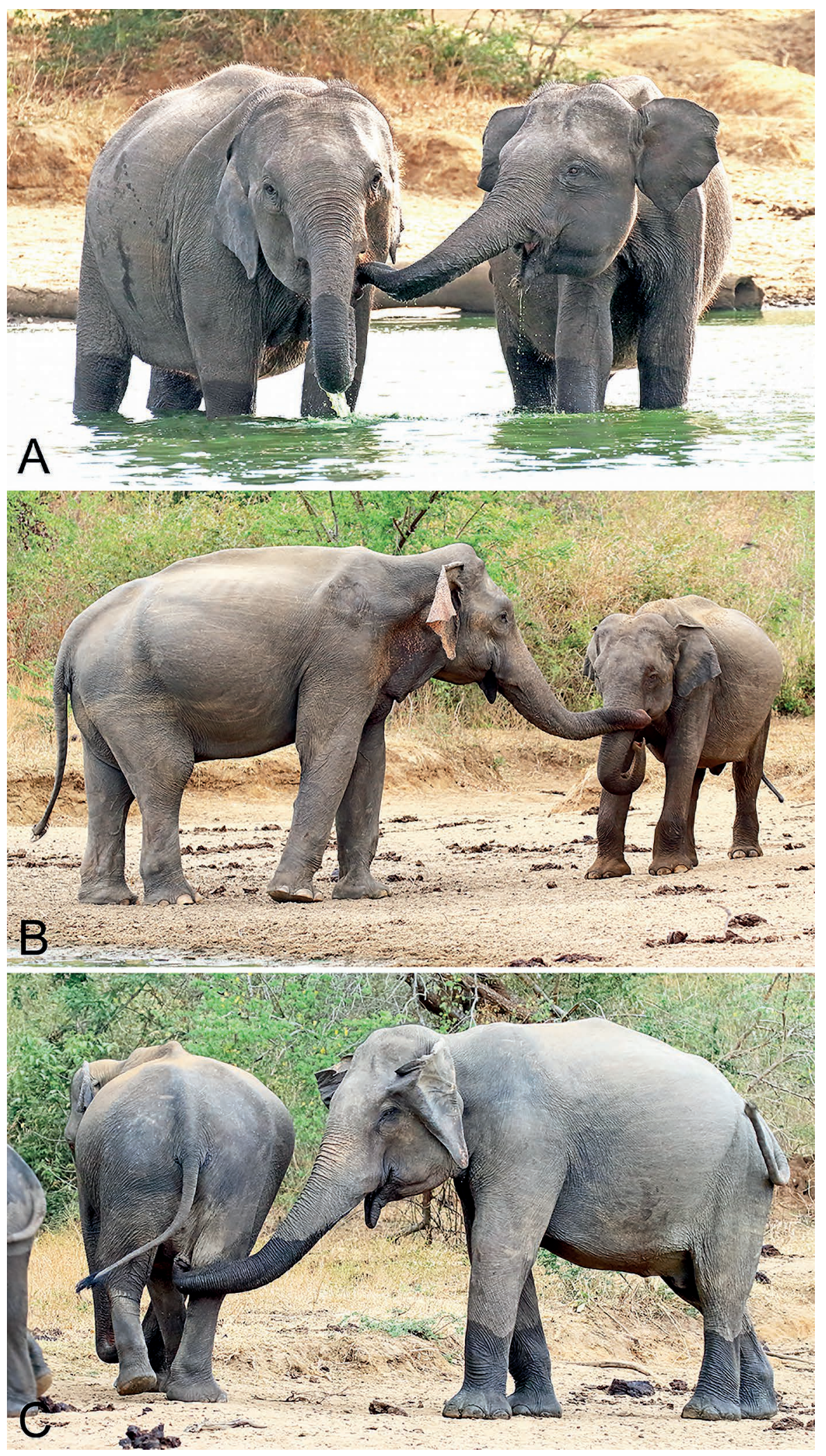

Fig. 2. Lateral trunk movements during social interactions. Lateralization was assess in trunk-tomouth contacts ( $\mathbf{a}-$ approach from behind, $\mathbf{b}-$ approach from the front, see Methods) and trunk-to-genitals contacts (c). 
the tip of the trunk) curling the trunk (approximately in the middle of its length) to the left or to the right, i.e. showed left- or right-sided trunk movement, respectively (Fig. 2). To clearly recognize the initiator of the trunk contact, the data were scored only from the elephants which intentionally approached the other from a distance (union or reunion). Lateral trunk movements were separately recorded for trunk-to-mouth contacts (for both males and females; Fig. 2a,b) which could be interpreted as greeting and recognition in the situations when individuals meet each other (e.g., Makecha et al., 2012), and trunk-to-genitals contacts (only for males touching females; Fig. 2c) likely having a socio-sexual context (e.g., physiological state inspection) in case of male-female interactions (e.g., Thitaram et al., 2009). Two types of approaches of the initiator to the percipient were distinguished for trunk-to-mouth contact: (1) approach from behind, i.e. elephants are in co-directed position (Fig. 2a), and approach from the front, i.e. elephants are in counter-directed position (Fig. 2b). All observed trunk-to-genitals contacts were performed after the approach from behind (Fig. 2c).

For data analysis the number of left-sided and right-sided trunk movements for each type of behaviour was scored. Data scored on multiple days for the same subject, if available, were pooled. In feeding, 50 lateral trunk uses were registered in each individual to make the dataset more comparable with those of the most recent previous study of lateralized trunk use in elephants (Keerthipriya et al., 2015). The individuals which less than 50 uses were discarded from the following analysis. In social interactions a single trunk contact from each individual was included in the analysis. For a subset of individuals two contacts were observed. These data were used to test a within-individual consistency between the trials. In that case, after a single social contact was registered the subsequent contact was taken into account only if the initiator of the interaction directed the trunk movement to another individual. In this behaviour, the collection of multiple events per individual sufficient for the assessment of individual preferences was not achieved, because it occurred relatively rare and was difficult to observe.

\section{STATISTICAL ANALYSIS}

For analysis of lateralization in feeding, we used the total number of lateral trunk uses obtained from each individual (see Table 1 and 2 for the distribution in each individual). According to a Shapiro-Wilk test, the data were not normally distributed, therefore nonparametric tests (two-sided) were used. Lateral preferences in trunk use at the individual level were estimated by comparing the number of left- and right-sided trunk movements (Fig. 1) in an individual using a binomial test. As a result, the individuals were classified as 'left-trunkers', 'right-trunkers' (Martin and Niemitz, 2003; Keerthipriya et al., 2015), or non-lateralized. A binomial test was used to evaluate the significance of differences between the number of left-trunkers and right-trunkers.

For the population-level analysis in feeding an individual lateralization index (LI) was calculated for each subject with the following formula: (left-sided trunk movements - right-sided trunk movements)/ the total number of lateral trunk movements. LI scores range from -1.0 to +1.0 , with negative values indicating the right-sided bias in trunk use and positive values the leftsided bias. We used the absolute value of each subject's lateralization indices to assess the strength of individual forelimb preference regardless of right or left direction. To examine the lateralization at the population level the significance of biases was examined using a one-sample Wilcoxon Signed-rank test. The Mann-Whitney $U$ test on LI scores was used to explore the influence of sex on lateralization. The Kruskal-Wallis test of independent samples (with post hoc Dunn's tests for between-pair comparisons) was carried out to estimate the effect of age class on the expression of lateralization.

The analysis of lateralization in trunk use during social interactions was based on single observations per individual. This type of analysis does not allow estimation of individual preferences, but is often used to assess the one-sided behavioural biases at the population level (Bourne and Todd, 2004; Siniscalchi et al., 2012; Karenina et al., 2017). The first observation of lateral trunk use from each individual was included in the analysis. The number of left-sided trunk movements and the number of right-sided trunk movements were compared using a binomial test. The significance level of alpha was set at 0.05 in all analyses.

\section{Results}

\section{PREFERENCES IN TRUNK MOVEMENTS DURING FEEDING}

All individuals studied showed significant lateral preferences in trunk movements during feeding (tearing off grass). Individual preferences were highly pronounced (binomial $z>2.69, P<0.007$; see Table 1 and 2), with exclusive preference for one side found in 35 elephants (42\%). Out of 83 animals, 36 subjects (43\%) displayed the left-side preference (left-trunkers), whereas $47 \mathrm{el}$ ephants $(57 \%)$ preferred the right side (right-trunkers; Fig. 3). No significant difference was found between the number of left-trunkers and right-trunkers $(z=-1.10, P=0.272)$. Analysis based on LI scores also failed to reveal a population-level lateralization (mean $\mathrm{HI} \pm \mathrm{SEM}=-0.13 \pm 0.10$; one-sample Wilcoxon Signedrank test: $Z=-470, P=0.283$ ). 
Table 1. Individual preferences in trunk movements during feeding in females

\begin{tabular}{|c|c|c|c|c|c|c|c|}
\hline Individual & Age & Left & Right & LI & $\mathbf{z}$ & $\mathbf{P}$ & Pref \\
\hline 1 & adult & 45 & 5 & 0.80 & 5.52 & $<0.001$ & $\mathrm{~L}$ \\
\hline 2 & adult & 2 & 48 & -0.92 & -6.36 & $<0.001$ & $\mathrm{R}$ \\
\hline 3 & adult & 42 & 8 & 0.68 & 4.67 & $<0.001$ & $\mathrm{~L}$ \\
\hline 4 & adult & 6 & 44 & -0.76 & -5.23 & $<0.001$ & $\mathrm{R}$ \\
\hline 5 & adult & 7 & 43 & -0.72 & -4.95 & $<0.001$ & $\mathrm{R}$ \\
\hline 6 & adult & 3 & 47 & -0.88 & -6.08 & $<0.001$ & $\mathrm{R}$ \\
\hline 7 & adult & 43 & 7 & 0.72 & 4.95 & $<0.001$ & $L$ \\
\hline 8 & adult & 50 & 0 & 1.00 & 6.93 & $<0.001$ & $L$ \\
\hline 9 & adult & 0 & 50 & -1.00 & -6.93 & $<0.001$ & $\mathrm{R}$ \\
\hline 10 & adult & 38 & 12 & 0.52 & 3.54 & $<0.001$ & $L$ \\
\hline 11 & adult & 4 & 46 & -0.84 & -5.80 & $<0.001$ & $\mathrm{R}$ \\
\hline 12 & adult & 4 & 46 & -0.84 & -5.80 & $<0.001$ & $\mathrm{R}$ \\
\hline 13 & adult & 47 & 3 & 0.88 & 6.08 & $<0.001$ & $L$ \\
\hline 14 & adult & 40 & 10 & 0.60 & 4.10 & $<0.001$ & $\mathrm{~L}$ \\
\hline 15 & adult & 45 & 5 & 0.80 & 5.52 & $<0.001$ & $\mathrm{~L}$ \\
\hline 16 & adult & 3 & 47 & -0.88 & -6.08 & $<0.001$ & $\mathrm{R}$ \\
\hline 17 & adult & 7 & 43 & -0.72 & -4.95 & $<0.001$ & $\mathrm{R}$ \\
\hline 18 & adult & 0 & 50 & -1.00 & -6.93 & $<0.001$ & $\mathrm{R}$ \\
\hline 19 & subadult & 43 & 7 & 0.72 & 4.95 & $<0.001$ & $L$ \\
\hline 20 & subadult & 8 & 42 & -0.68 & -4.67 & $<0.001$ & $\mathrm{R}$ \\
\hline 21 & subadult & 2 & 48 & -0.92 & -6.36 & $<0.001$ & $\mathrm{R}$ \\
\hline 22 & subadult & 40 & 10 & 0.60 & 4.10 & $<0.001$ & $L$ \\
\hline 23 & subadult & 50 & 0 & 1.00 & 6.93 & $<0.001$ & $\mathrm{~L}$ \\
\hline 24 & subadult & 48 & 2 & 0.92 & 6.36 & $<0.001$ & $\mathrm{~L}$ \\
\hline 25 & subadult & 50 & 0 & 1.00 & 6.93 & $<0.001$ & $\mathrm{~L}$ \\
\hline 26 & subadult & 0 & 50 & -1.00 & -6.93 & $<0.001$ & $\mathrm{R}$ \\
\hline 27 & subadult & 3 & 47 & -0.88 & -6.08 & $<0.001$ & $\mathrm{R}$ \\
\hline 28 & subadult & 6 & 44 & -0.76 & -5.23 & $<0.001$ & $\mathrm{R}$ \\
\hline 29 & subadult & 0 & 50 & -1.00 & -6.93 & $<0.001$ & $\mathrm{R}$ \\
\hline 30 & subadult & 0 & 50 & -1.00 & -6.93 & $<0.001$ & $\mathrm{R}$ \\
\hline 31 & subadult & 3 & 47 & -0.88 & -6.08 & $<0.001$ & $\mathrm{R}$ \\
\hline 32 & subadult & 41 & 9 & 0.64 & 4.38 & $<0.001$ & $\mathrm{~L}$ \\
\hline 33 & juvenile & 50 & 0 & 1.00 & 6.93 & $<0.001$ & $\mathrm{~L}$ \\
\hline 34 & juvenile & 10 & 40 & -0.60 & -4.10 & $<0.001$ & $\mathrm{R}$ \\
\hline 35 & juvenile & 48 & 2 & 0.92 & 6.36 & $<0.001$ & $\mathrm{~L}$ \\
\hline 36 & juvenile & 0 & 50 & -1.00 & -6.93 & $<0.001$ & $\mathrm{R}$ \\
\hline 37 & juvenile & 50 & 0 & 1.00 & 6.93 & $<0.001$ & $L$ \\
\hline 38 & juvenile & 50 & 0 & 1.00 & 6.93 & $<0.001$ & $\mathrm{~L}$ \\
\hline 39 & juvenile & 1 & 49 & -0.96 & -6.65 & $<0.001$ & $\mathrm{R}$ \\
\hline 40 & juvenile & 2 & 48 & -0.92 & -6.36 & $<0.001$ & $\mathrm{R}$ \\
\hline 41 & juvenile & 50 & 0 & 1.00 & 6.93 & $<0.001$ & $\mathrm{~L}$ \\
\hline 42 & juvenile & 8 & 42 & -0.68 & -4.67 & $<0.001$ & $\mathrm{R}$ \\
\hline 43 & juvenile & 4 & 46 & -0.84 & -5.80 & $<0.001$ & $\mathrm{R}$ \\
\hline 44 & juvenile & 0 & 50 & -1.00 & -6.93 & $<0.001$ & $\mathrm{R}$ \\
\hline 45 & calf & 0 & 50 & -1.00 & -6.93 & $<0.001$ & $\mathrm{R}$ \\
\hline 46 & calf & 50 & 0 & 1.00 & 6.93 & $<0.001$ & $\mathrm{~L}$ \\
\hline 47 & calf & 3 & 47 & -0.88 & -6.08 & $<0.001$ & $\mathrm{R}$ \\
\hline 48 & calf & 6 & 44 & -0.76 & -5.23 & $<0.001$ & $\mathrm{R}$ \\
\hline 49 & calf & 45 & 5 & 0.80 & 5.52 & $<0.001$ & $\mathrm{~L}$ \\
\hline 50 & calf & 0 & 50 & -1.00 & -6.93 & $<0.001$ & $\mathrm{R}$ \\
\hline 51 & calf & 0 & 50 & -1.00 & -6.93 & $<0.001$ & $\mathrm{R}$ \\
\hline
\end{tabular}

Left: number of left-sided trunk movements; Right: number of rightsided trunk movements; LI: laterality index; z: binomial z score, positive values indicate leftward bias, negative values indicate rightward bias; Pref: lateral position preference; L: left-sided preference; R: rightsided preference.
Table 2. Individual preferences in trunk movements during feeding in males

\begin{tabular}{|c|c|c|c|c|c|c|c|}
\hline Individual & Age & Left & Right & LI & $z$ & $\mathbf{P}$ & Pref \\
\hline 52 & adult & 50 & 0 & 1.00 & 6.93 & $<0.001$ & L \\
\hline 53 & adult & 0 & 50 & -1.00 & -6.93 & $<0.001$ & $\mathrm{R}$ \\
\hline 54 & adult & 0 & 50 & -1.00 & -6.93 & $<0.001$ & $\mathrm{R}$ \\
\hline 55 & adult & 0 & 50 & -1.00 & -6.93 & $<0.001$ & $\mathrm{R}$ \\
\hline 56 & adult & 50 & 0 & 1.00 & 6.93 & $<0.001$ & $\mathrm{~L}$ \\
\hline 57 & adult & 6 & 44 & -0.76 & -5.23 & $<0.001$ & $\mathrm{R}$ \\
\hline 58 & adult & 9 & 41 & -0.64 & -4.38 & $<0.001$ & $\mathrm{R}$ \\
\hline 59 & adult & 50 & 0 & 1.00 & 6.93 & $<0.001$ & $\mathrm{~L}$ \\
\hline 60 & adult & 46 & 4 & 0.84 & 5.80 & $<0.001$ & L \\
\hline 61 & adult & 1 & 49 & -0.96 & -6.65 & $<0.001$ & $\mathrm{R}$ \\
\hline 62 & adult & 3 & 47 & -0.88 & -6.08 & $<0.001$ & $\mathrm{R}$ \\
\hline 63 & subadult & 0 & 50 & -1.00 & -6.93 & $<0.001$ & $\mathrm{R}$ \\
\hline 64 & subadult & 50 & 0 & 1.00 & 6.93 & $<0.001$ & $L$ \\
\hline 65 & subadult & 0 & 50 & -1.00 & -6.93 & $<0.001$ & $\mathrm{R}$ \\
\hline 66 & subadult & 50 & 0 & 1.00 & 6.93 & $<0.001$ & L \\
\hline 67 & subadult & 50 & 0 & 1.00 & 6.93 & $<0.001$ & L \\
\hline 68 & subadult & 49 & 1 & 0.96 & 6.65 & $<0.001$ & L \\
\hline 69 & subadult & 43 & 7 & 0.72 & 4.95 & $<0.001$ & L \\
\hline 70 & juvenile & 48 & 2 & 0.92 & 6.36 & $<0.001$ & L \\
\hline 71 & juvenile & 0 & 50 & -1.00 & -6.93 & $<0.001$ & $\mathrm{R}$ \\
\hline 72 & juvenile & 6 & 44 & -0.76 & -5.23 & $<0.001$ & $\mathrm{R}$ \\
\hline 73 & juvenile & 35 & 15 & 0.40 & 2.69 & 0.007 & $L$ \\
\hline 74 & juvenile & 0 & 50 & -1.00 & -6.93 & $<0.001$ & $\mathrm{R}$ \\
\hline 75 & juvenile & 50 & 0 & 1.00 & 6.93 & $<0.001$ & L \\
\hline 76 & juvenile & 50 & 0 & 1.00 & 6.93 & $<0.001$ & L \\
\hline 77 & juvenile & 4 & 46 & -0.84 & -5.80 & $<0.001$ & $\mathrm{R}$ \\
\hline 78 & juvenile & 8 & 42 & -0.68 & -4.67 & $<0.001$ & $\mathrm{R}$ \\
\hline 79 & calf & 2 & 48 & -0.92 & -6.36 & $<0.001$ & $\mathrm{R}$ \\
\hline 80 & calf & 0 & 50 & -1.00 & -6.93 & $<0.001$ & $\mathrm{R}$ \\
\hline 81 & calf & 50 & 0 & 1.00 & 6.93 & $<0.001$ & $L$ \\
\hline 82 & calf & 1 & 49 & -0.96 & -6.65 & $<0.001$ & $\mathrm{R}$ \\
\hline 83 & calf & 42 & 8 & 0.68 & 4.67 & $<0.001$ & $\mathrm{~L}$ \\
\hline
\end{tabular}

Legend as in Table 1.

Neither the subjects' sex nor the age class were found to have a significant influence on the direction of lateralization in feeding (sex: Mann-Whitney $U$ test: $U=769.0, P=0.660$; age: Kruskal-Wallis test: $\mathrm{H}=1.85$, $P=0.604)$. Similarly, the elephants' sex and age class had no significant effect on the strength of the one-sided preferences (sex: $U=644.0, P=0.095$; age: $\mathrm{H}=2.76$, $P=0.430)$.

The results of the present study were compared with the results obtained by Martin and Niemitz (2003) on the same elephant population to examine the stability of lateralization pattern over time. The proportion of right-trunkers and left-trunkers did not differ significantly between two studies: $51 \%$ of right-trunkers out of 41 subjects (Martin and Niemitz 2003) vs. 57\% of right-trunkers out of 83 subjects (our study) (twoproportion $z$ test: $z=-0.63, P=0.528$ ). Consistency of lateralization between different elephant populations was tested by comparison of our results with those ob- 


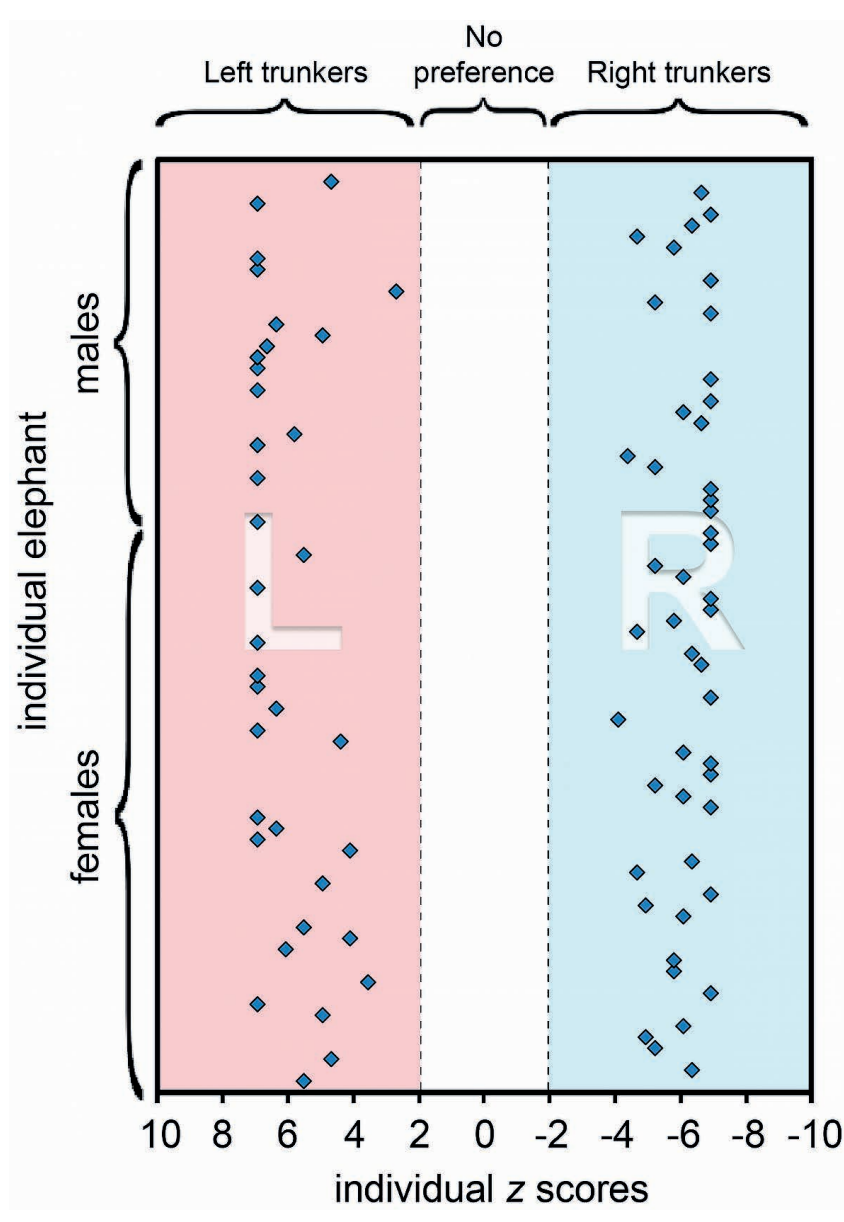

Fig. 3. The distribution of individual preferences $(n=83)$ for trunk use in feeding. Based on individual $z$ scores, each elephant (blue diamonds) was classified as a left-trunker or right-trunker. No sex difference was found either in the direction or the strength of lateralization (see Results).

tained by Keerthipriya et al. (2015) on Asian elephant population in southern India. The proportion of righttrunkers and left-trunkers did not differ significantly between two populations: $51 \%$ of right-trunkers out of 196 subjects (Keerthipriya et al., 2015) vs. $57 \%$ of righttrunkers out of 83 subjects (our study) (two-proportion $z$ test: $z=-0.99, P=0.321)$.

\section{PREFERENCES IN TRUNK MOVEMENTS DURING SOCIAL INTERACTIONS}

Analysis failed to reveal a significant population-level preference in trunk movements during trunk-to-mouth contacts in both types of approaches of the initiator to the recipient (approach from behind: 18 left-sided and 21 right-sided trunk uses, binomial $z=-0.32, P=0.749$; approach from the front: 14 left-sided and 11 right-sided uses, binomial $z=0.40, P=0.690$; Fig. 2a,b). To test within-individual consistency we compared the first and the second trunk-to-mouth contacts of the same initiator (but directed to different recipients). In the majority of subjects the trunk movements in two trunk-to-mouth contacts were oppositely directed (approach from behind: 16 out of 20 subjects, $z=2.46, P=0.012$; approach from the front: 14 out of 17 subjects, $z=2.43, P=0.013$ ). In a pooled dataset from 44 males 20 females, analysis $(2 \times 2$ contingency table $)$ showed no significant association between the elephants' sex and the direction of the trunk-to-mouth contact ( $P=0.419$, Fisher's exact test).

In contrast, trunk movements during trunk-to-genitals contact were lateralized at the population level. In the majority of observations male elephants performed right-sided trunk movement when touching female ( 20 out of 23 uses; binomial $z=-3.34, P<0.001$; Fig. 2 c). Two contacts performed by the same males but directed to different females were compared. In the majority of males the direction of trunk movements was the same between two trunk-to-genitals contacts ( 10 out of $11 \mathrm{ob}-$ servations, binomial $z=-2.41, P=0.012$ ).

\section{Discussion}

In this study, wild Asian elephants showed strong individual-level lateralization of trunk movements during feeding (see Fig. 3), while no population-level preference was revealed. The comparison of the present and previous studies on wild Asian elephants showed the distribution of right- and left-trunkers to be conserved both in the same population over time (Martin and Niemitz, 2003) and across two geographically distinct populations (Keerthipriya et al., 2015). Trunk use during feeding has been also studied in a smaller sample of captive elephants with similar pattern of lateralization found (Haakonsson and Semple, 2009). Thus, our results corroborate previous research conducted on wild and captive Asian elephants. In summary, $100 \%$ of individuals were lateralized for feeding-related trunk movements (see Methods) in all four studies conducted. It is reasonable to conclude that robust individual lateral preferences for feeding, combined with the absence of one-sided population bias, is species-typical characteristic of Asian elephants. Notably, manatees, which are closely related to elephants, show similar pattern of motor lateralization with pronounced flipper preferences at the individual, but not population level (Tyler-Julian et al., 2016).

Analysis based on single observations per individual showed no population-level bias in elephant trunk movements during trunk-to-mouth contacts - social behaviour which may serve as greeting and recognition when individuals meet each other (e.g., Makecha et al., 2012). This result was consistent when the initiator approached the recipient from behind and when the initiator approached the recipient from the front. The influence of the position of the recipient on the trunk movement of the initiator is an important issue for future 
research. Individual preferences were not investigated, and it is possible that lateralization of trunk-to-mouth contacts occurs at the individual level. However, in the majority of subjects, the direction of trunk movements was inconsistent between the two contacts. Although many aspects of mammalian social behaviour are lateralized at the population level (Brancucci et al., 2009; Rosa Salva et al., 2009), the absence of population-level lateralization in elephants' trunk-to-mouth contacts, is not exceptional. Chimpanzees (Prieur et al., 2016a), gorillas (Prieur et al., 2016b) and orangutans (Rogers and Kaplan, 1996) show no population-level hand preference when touching conspecifics. Similarly, another manipulative behaviour directed to social partners allogrooming - is not lateralized in chimpanzees (Hopkins et al., 2007). It is possible, however, that we failed to reveal population-level lateralization in trunk-to-mouth contacts because this is relatively nonspecific type of social interactions, which may have different significance for different categories of individuals (e.g., familiar and non-familiar, related and non-related, etc.). Populationlevel bias in trunk use during trunk-to-mouth contacts can potentially be found in more specific contexts and specific categories of interacting elephants.

In contrast to trunk-to-mouth contacts, we did find population-level lateralization in trunk-to-genitals contacts between male initiator and female recipient. This type of interactions is likely a part of male sexual behavior serving for the inspection of female's physiological state (e.g., Thitaram et al., 2009). Based on single observations per individual we found the right-sided bias in males touching females. Curiously, in one of his forms, Ganesha, elephant-headed Hindu deity, is depicted with the trunk curved to the right (see Fig. 4). This right-trunked representation of the deity is said to be associated to the sun, power and masculine energy; while the left-trunked representation has different spiritual meaning (Grimes, 1995; Bhavanani, 2007; Grewal, 2010). We speculate that perhaps this cultural artefact is based on the long history of observing captive male elephants in South Asia. The association between right-trunked Ganesha and powerful masculine energy may have appeared as a result of observing male elephants showing right-sided trunk movements during interactions with females.

In the course of ontogenesis, the elephant's trunk develops by a fusion of the upper lip and nose (Shoshani, 1998). Therefore, it is reasonable to suggest that lateralization revealed in trunk movements during malefemale contacts may potentially be analogous to asymmetric facial expression of emotions typical for human and non-human primates (e.g., Fernández-Carriba et al., 2002). The direction of bias in facial expressions (greater involvement of the left side of the face), however, is opposite to that observed in elephants' trunk contacts. More likely, lateralized trunk-to-genitals contacts



Fig. 4. Elephant-headed Hindu deity, Ganesha, with the trunk curved to the right.

reflect the lateralization of olfactory system. As a result of a right-sided trunk movement the male's right nostril is presumably closer to female's genitals and is more involved in perception of chemical signals. The prevalence of right-sided trunk movements in males may thus derive from the preference to use the right nostril to smell female's genitals. Olfactory neurons project their input ipsilaterally, i.e. from each nostril to the brain hemisphere on the same side (Royet and Plailly, 2004); therefore, the right nostril preference in trunk-to-genitals contacts suggests the superiority of the right hemisphere in the processing of socially relevant olfactory information in elephants. Previous studies have shown similar pattern of olfactory lateralization in chicks, dogs, horses and humans (reviewed in Siniscalchi, 2017). Horses, for instance, preferentially use the right nostril to sniff social odors such as of stallion's feces (McGreevy \& Rogers, 2005) and urine of an oestrous mare (Siniscalchi et al., 2015). If the right-sided bias in socio-sexual elephants' behaviour is linked to lateralized olfactory perception, it corresponds to the general pattern of social lateraliza- 
tion in mammals (Brancucci et al., 2009; Rosa Salva et al., 2009; Rogers et al., 2013). At the same time, the impact of other sensory modalities besides olfaction on the origination of the revealed lateralization cannot be excluded. In addition, the lateralization could potentially reflect acquired responses of the males to preferences of the females whom they are approaching. Such conventions may allow females to accurately assess the intentions of males and classify them as non-hostile.

Our findings indicate that at least some types of social behaviour, such as male-female socio-sexual contacts, elicit population-level lateralization of trunk use in elephants as opposed to non-social behaviour such as feeding. Trunk preferences in feeding and social interactions were tested using different methods - multiple and single observations, respectively. It is unlikely, however, that this can explain the difference in results between the behaviours. The previous study of lateralized social behaviour has found the results of analyses based on multiple and single observations to be consistent in a wide range of mammal species studied (Karenina et al., 2017). In addition, in the majority of observations, the direction of trunk movements was the same in two subsequent trunk-to-genitals contacts performed by the same male. This may imply that, much like in feeding, in socio-sexual behaviour elephants display the individuallevel lateralization in trunk use. For full understanding of trunk lateralization further investigation based on a greater number of events is needed to test whether a population-level bias in the distribution of individual preferences occurs in Asian elephants.

The results of the present study suggest that social context favours the manifestation of population-level lateralization in elephants. This is in line with the general tendency observed in mammals. In primates, communicative motor actions, such as manual gestures, elicit more pronounced lateralization compared to non-communicative actions (Meguerditchian et al., 2013). Evidence for the absence of the population-level lateralization in non-social forelimb use has been reported in many nonprimate mammals, e.g., horses, Equus caballus (Austin and Rogers, 2012), dogs, Canis familiaris (Poyser et al., 2006, but see Wells, 2003 for subgroup biases in males and females), and bottlenose dolphins, Tursiops aduncus (Sakai et al., 2006). The same species, however, showed pronounced lateralization at the population level in social behaviours (horses: e.g., Austin and Rogers, 2012, Karenina et al., 2017; bottlenose dolphins: e.g., Sakai et al., 2006; dogs: reviewed in Siniscalchi and Quaranta, 2014). Our findings support the theory stating that since uniformity in side preferences within a population is relevant for social coordination, population-level biases are more likely to occur in social behaviour (Ghirlanda and Vallortigara, 2004; Vallortigara and Rogers, 2005; Ghirlanda et al., 2009; MacNeilage et al., 2009).
In conclusion, here we provide the first evidence for the population-level lateralization of trunk use in elephants. Our findings demonstrate that lateralized trunk use is not so simple and can be manifested in various forms. Firstly, it occurs in form of relatively simple motor actions lateralized only at the individual level as it is shown for feeding-related behaviours. Secondly, lateralization in the use of the trunk can be displayed in social interactions in form of population-level perceptual bias likely associated with the hemispheric lateralization. The results of the present study, together with previous findings (e.g., Rogers, 2009; Austin and Rogers, 2012; Tyler-Julian et al., 2016), demonstrate that the brain and behaviour lateralization can be manifested in a species without being pronounced in some motor actions. Therefore, a variety of behaviours should be investigated, with special attention to socially relevant actions, to characterize lateralization in a species.

\section{Acknowledgements}

We gratefully thank field staff of the Uda Walawe Elephant Research Project and Uda Walawe National Park personnel. Work was conducted with the approval of St. Petersburg State University ethical committee (permit no. 131-03-5).

\section{References}

Afonso, D., Santana, C., and Rodriguez, M. (1993). Neonatal lateralization of behavior and brain dopaminergic asymmetry. Brain Research Bulletin, 32(1), 11-16. doi: 10.1016/0361-9230(93)90312-Y

Arivazhagan, C., and Sukumar, R. (2008). Constructing age structures of Asian elephant populations: A comparison of two field methods of age estimation. Gajah, 29, 11-16.

Austin, N. P., and Rogers, L.J. (2012). Limb preferences and lateralization of aggression, reactivity and vigilance in feral horses, Equus caballus. Animal Behaviour, 83(1), 239-247. doi: 10.1016/j.anbehav.2011.10.033

Bhavanani, A. B. Swarodaya Vigjnan. (2007). A scientific study of the nasal cycle. Yoga Mimamsa, 39, 32-38.

Bourne, V.J., and Todd, B. K. (2004). When left means right: An explanation of the left cradling bias in terms of right hemisphere specializations. Developmental Science, 7(1), 19-24. doi: 10.1111/j.1467-7687.2004.00318.x

Brancucci, A., Lucci, G., Mazzatenta, A., and Tommasi, L. (2009). Asymmetries of the human social brain in the visual, auditory and chemical modalities. Philosophical Transactions of the Royal Society of London B: Biological Sciences, 364(1519), 895-914. doi: 10.1098/rstb.2008.0279

de Silva, S., Ranjeewa, A. D., and Weerakoon, D. (2011). Demography of Asian elephants (Elephas maximus) at Uda Walawe National Park, Sri Lanka based on identified individuals. Biological Conservation, 144(5), 1742-1752. doi: 10.1016/j.biocon.2011.03.011

Denenberg, V. H., and Yutzey, D. A. (1985). Hemispheric laterality, behavioral asymmetry, and the effects of early experience in rats. In S. D. Glick (Ed), Cerebral lateralization in nonhuman species (pp. 109-133). Orlando, Fl: Academic Press

Espmark, Y., and Kinderås, K. (2002). Behavioural lateralisation in reindeer. Rangifer, 22(1), 51-59. doi: 10.7557/2.22.1.687 
Fernández-Carriba, S., Loeches, Á., Morcillo, A., and Hopkins, W. D. (2002). Asymmetry in facial expression of emotions by chimpanzees. Neuropsychologia, 40(9), 1523-1533. doi: 10.1016/S0028-3932(02)00028-3

Forrester, G.S., Crawley, M., and Palmer, C. (2014a). Social environment elicits lateralized navigational paths in two populations of typically developing children. Brain and Cognition, 91, 21-27. doi: 10.1016/j.bandc.2014.07.005

Forrester, G. S., Pegler, R., Thomas, M.S., and Mareschal, D. (2014b). Handedness as a marker of cerebral lateralization in children with and without autism. Behavioural Brain Research, 268, 14-21. doi: 10.1016/j. bbr.2014.03.040

Forrester, G. S., Quaresmini, C., Leavens, D. A., Mareschal, D., \& Thomas, M. S. (2013). Human handedness: an inherited evolutionary trait. Behavioural Brain Research, 237, 200-206. doi: 10.1016/j.bbr.2012.09.037

Giljov, A., Karenina, K., Ingram, J., and Malashichev, Y. (2015). Parallel emergence of true handedness in the evolution of marsupials and placentals. Current Biology, 25(14), 1878-1884. doi: 10.1016/j.cub.2015.05.043

Ghirlanda, S., Frasnelli, E., and Vallortigara, G. (2009). Intraspecific competition and coordination in the evolution of lateralization. Philosophical Transactions of the Royal Society of London B: Biological Sciences, 364(1519), 861-866. doi: 10.1098/rstb.2008.0227

Ghirlanda, S., and Vallortigara, G. (2004). The evolution of brain lateralization: a game-theoretical analysis of population structure. Proceedings of the Royal Society of London B: Biological Sciences, 271(1541), 853-858. doi: 10.1098/rspb.2003.2669

Grewal, R. (2010). The Book of Ganesha. London: Penguin.

Grimes, J. A. (1995). Ganapati: Song of the self. Albany: State University of New York Press.

Haakonsson, J.E., and Semple, S. (2009). Lateralization of trunk movements in captive Asian elephants (Elephas maximus). Laterality, 14(4), 413-422. doi: 10.1080/13576500802572442

Hanbury, D. B., Edens, K. D., Bunch, D. A., Legg, C. E., and Watson, S. L. (2010). Multiple measures of laterality in Garnett's bushbaby (Otolemur garnettii). American Journal of Primatology, 72(3), 206-216. doi: 10.1002/ajp.20769

Harris, L. J. (1989). Footedness in parrots: three centuries of research, theory, and mere surmise. Canadian Journal of Psychology, 43(3), 369-396. doi: 10.1037/h0084228

Hellige, J. B. (1993). Unity of thought and action: varieties of interaction between the left and right hemispheres. Current Directions in Psychological Science, 2, 21-25. doi: 10.1111/1467-8721.ep10770559

Hook, M. A. (2004). The evolution of lateralized motor functions. In L.J. Rogers, and G. Kaplan (Eds.), Comparative vertebrate cognition (pp. 325-370). New York: Kluwer Academic / Plenum Publishing.

Hopkins, W. D., Russell, J. L., Remkus, M., Freeman, H., and Schapiro, S. J. (2007). Handedness and grooming in Pan troglodytes: comparative analysis between findings in captive and wild individuals. International Journal of Primatology, 28(6), 1315-1326. doi: 10.1007/s10764-0079221-x

Karenina, K., Giljov, A., Ingram, J., Rowntree, V.J., and Malashichev, Y. (2017). Lateralization of mother-infant interactions in a diverse range of mammal species. $\mathrm{Na}$ ture Ecology \& Evolution, 1, 0030. doi: 10.1038/s41559016-0030

Karenina, K. A., Giljov, A. N., and Malashichev, Y. B. (2013). Eye as a key element of conspecific image eliciting lateralized response in fish. Animal Cognition, 16(2), 287-300. doi:10.1007/s10071-012-0572-0
Keerthipriya, P., Tewari, R., and Vidya, T. N. C. (2015). Lateralization in trunk and forefoot movements in a population of free-ranging Asian elephants (Elephas maximus). Journal of Comparative Psychology, 129(4), 377-387. doi: 10.1037/com0000013

Laska, M., and Tutsch, M. (2000). Laterality of tail resting posture in three species of New World primates. Neuropsychologia, 38(7), 1040-1046. doi: 10.1016/S00283932(99)00147-5

Loizi, H., Goodwin, T. E., Rasmussen, L. E. L., Whitehouse, A. M. and Schulte, B. A. (2009). Sexual dimorphism in the performance of chemosensory investigatory behaviours by African elephants (Loxodonta africana). Behaviour, 146(3), 373-392. doi: 10.1163/156853909X410964

Lorincz, E., and Fabre-Thorpe, M. (1996). Shift of laterality and compared analysis of paw performances in cats during practice of a visuomotor task. Journal of Comparative Psychology, 110(3), 307-315. doi: 10.1037/07357036.110.3.307

MacNeilage, P. F., Rogers, L. J., and Vallortigara, G. (2009). Origins of the left \& right brain. Scientific American, 301(1), 60-67. doi: 10.1038/scientificamerican0709-60

Magat, M., and Brown, C. (2009). Laterality enhances cognition in Australian parrots. Proceedings of the Royal Society of London B: Biological Sciences, 276(1676), 4155-4162. doi: 10.1098/rspb.2009.1397

Makecha, R., Fad, O., and Kuczaj II, S. A. (2012). The Role of Touch in the Social Interactions of Asian Elephants (Elephas maximus). International Journal of Comparative Psychology, 25(1), 60-82.

Malashichev, Y. B. (2006). One-sided limb preference is linked to alternating-limb locomotion in anuran amphibians. Journal of Comparative Psychology, 120(4), 401-410. doi: 10.1037/0735-7036.120.4.401

Mangalam, M., Desai, N., and Singh, M. (2014). Division of labor in hand usage in free-ranging bonnet macaques, Macaca radiata. American Journal of Primatology, 76(6), 576-585. doi: 10.1002/ajp.22250

Martin, F., and Niemitz, C. (2003). "Right-trunkers" and" left-trunkers": side preferences of trunk movements in wild Asian elephants (Elephas maximus). Journal of Comparative Psychology, 117(4), 371-379. doi: 10.1037/0735-7036.117.4.371

McGreevy, P.D., and Rogers, L.J. (2005). Motor and sensory laterality in thoroughbred horses. Applied Animal Behaviour Science, 92(4), 337-352. doi: 10.1016/j.applanim.2004.11.012

McGrew, W. C., and Marchant, L. F. (1999). Laterality of hand use pays off in foraging success for wild chimpanzees. Primates, 40(3), 509-513. doi: 10.1007/BF02557586

Meguerditchian, A., Vauclair, J., and Hopkins, W. D. (2013). On the origins of human handedness and language: a comparative review of hand preferences for bimanual coordinated actions and gestural communication in nonhuman primates. Developmental Psychobiology, 55(6), 637-650. doi: 10.1002/dev.21150

Mutha, P. K., Haaland, K. Y., and Sainburg, R. L. (2013). Rethinking motor lateralization: specialized but complementary mechanisms for motor control of each arm. PLOS ONE, 8(3), e58582. doi: 10.1371/journal.pone.0058582

Nudo, R. J., Jenkins, W. M., Merzenich, M. M., Prejean, T., and Grenda, R. (1992). Neurophysiological correlates of hand preference in primary motor cortex of adult squirrel monkeys. Journal of Neuroscience, 12(8), 2918-2947.

Perelle, I. B., and Ehrman, L. (1994). An international study of human handedness: the data. Behavior Genetics, 24(3), 217-227. doi: 10.1007/BF01067189

Phillips, K. A., Schaeffer, J., Barrett, E., and Hopkins, W. D. (2013). Performance asymmetries in tool use are associ- 
ated with corpus callosum integrity in chimpanzees (Pan troglodytes): a diffusion tensor imaging study. Behavioral Neuroscience, 127(1), 106-113. doi: 10.1037/a0031089

Poyser, F., Caldwell, C., and Cobb, M. (2006). Dog paw preference shows lability and sex differences. Behavioural Processes, 73(2), 216-221. doi: 10.1016/j.beproc.2006.05.011

Prieur, J., Pika, S., Barbu, S., and Blois-Heulin, C. (2016a). A multifactorial investigation of captive chimpanzees' intraspecific gestural laterality. Animal Behaviour, 116, 31-43. doi: 10.1016/j.anbehav.2016.03.024

Prieur, J., Pika, S., Barbu, S., and Blois-Heulin, C. (2016b). Gorillas are right-handed for their most frequent intraspecific gestures. Animal Behaviour, 118, 165-170. doi: 10.1016/j. anbehav.2016.06.008

Quaranta, A., Siniscalchi, M., and Vallortigara, G. (2007). Asymmetric tail-wagging responses by dogs to different emotive stimuli. Current Biology, 17(6), R199-R201. doi: 10.1016/j.cub.2007.02.008

Quaresmini, C., Forrester, G. S., Spiezio, C., and Vallortigara, G. (2014). Social environment elicits lateralized behaviors in gorillas (Gorilla gorilla gorilla) and chimpanzees (Pan troglodytes). Journal of Comparative Psychology, 128(3), 276-284. doi: 10.1037/a0036355

Racine, R. A. (1980). Behavior associated with feeding in captive African and Asian elephants. Elephant (Supplement), 1, 57-71.

Rasmussen, L. E. L., and Schulte, B.A. (1998). Chemical signals in the reproduction of Asian (Elephas maximus) and African (Loxodonta africana) elephants. Animal Reproduction Science, 53(1), 19-34. doi: 10.1016/S03784320(98)00124-9

Reimchen, T. E., and Spoljaric, M. A. (2011). Right paw foraging bias in wild black bear (Ursus americanus kermodei). Laterality, 16, 471-478. doi: 10.1080/1357650X.2010.485202

Rogers, L. J. (2009). Hand and paw preferences in relation to the lateralized brain. Philosophical Transactions of the Royal Society of London B: Biological Sciences, 364(1519), 943-954. doi: 10.1098/rstb.2008.0225

Rogers, L.J., and Kaplan, G. (1996). Hand preferences and other lateral biases in rehabilitated orang-utans, Pongo pygmaeus pygmaeus. Animal Behaviour, 51(1), 13-25. doi: 10.1006/anbe.1996.0002

Rogers, L .J., and Vallortigara, G. (2017). Lateralized brain functions: methods in human and non-human species. New York: Springer.

Rogers, L. J., Vallortigara, G., and Andrew, R. J. (2013). Divided brains: the biology and behaviour of brain asymmetries. Cambridge: Cambridge University Press.

Rosa Salva, O., Regolin, L., Mascalzoni, E., and Vallortigara, G. (2012). Cerebral and behavioural asymmetries in animal social recognition. Comparative Cognition \& Behavior Reviews, 7, 110-138. doi: 10.3819/ccbr.2012.70006

Royet, J.P., and Plailly, J. (2004). Lateralization of olfactory processes. Chemical Senses, 29(8), 731-745. doi: 10.1093/ chemse/bjh067

Sakai, M., Hishii, T., Takeda, S., and Kohshima, S. (2006). Laterality of flipper rubbing behaviour in wild bottlenose dolphins (Tursiops aduncus): Caused by asymmetry of eye use?. Behavioural Brain Research, 170(2), 204-210. doi: 10.1016/j.bbr.2006.02.018

Shabbott, B. A., and Sainburg, R. L. (2008). Differentiating between two models of motor lateralization. Journal of Neurophysiology, 100(2), 565-575. doi: 10.1152/jn.90349.2008

Shoshani, J. (1998). Understanding proboscidean evolution: a formidable task. Trends in Ecology \& Evolution, 13(12), 480-487. doi: 10.1016/S0169-5347(98)01491-8

Shoshani, J., Kupsky, W.J., and Marchant, G. H. (2006). Elephant brain: Part I: Gross morphology, functions, comparative anatomy, and evolution. Brain Research Bulletin, 70(2), 124-157. doi: 10.1016/j.brainresbull.2006.03.016

Siniscalchi, M. (2017). Olfactory lateralization. In L. Rogers, and G. Vallortigara (Eds.), Lateralized brain functions: methods in human and non-human species (pp. 103-120). New York: Springer.

Siniscalchi, M., and Quaranta, A. (2014). Wagging to the right or to the left: lateralization and what it tells of the dog's social brain. In J. Kaminski, and S. Marshall-Pescini (Eds.), The social dog: behavior and cognition (pp. 373-393). Amsterdam: Elsevier.

Siniscalchi, M., Dimatteo, S., Pepe, A. M., Sasso, R., and Quaranta, A. (2012). Visual lateralization in wild striped dolphins (Stenella coeruleoalba) in response to stimuli with different degrees of familiarity. PLOS ONE, 7(1), e30001. doi: 10.1371/journal.pone.0030001

Siniscalchi, M., Padalino, B., Aubé, L., and Quaranta, A. (2015). Right-nostril use during sniffing at arousing stimuli produces higher cardiac activity in jumper horses. Laterality, 20(4), 483-500. doi: 10.1080/1357650X.2015.1005629

Ströckens, F., Güntürkün, O., and Ocklenburg, S. (2013). Limb preferences in non-human vertebrates. Laterality, 18(5), 536-575. doi: 10.1080/1357650X.2012.723008

Thitaram, C., Chansitthiwet, S., Pongsopawijit, P., Brown, J. L., Wongkalasin, W., Daram, P., ... and Colenbrander, B. (2009). Use of genital inspection and female urine tests to detect oestrus in captive Asian elephants. Animal Reproduction Science, 115(1), 267-278. doi: 10.1016/j.anireprosci.2008.11.017

Tyler-Julian, K., Chapman, K. M., Frances, C., and Bauer, G. B. (2016). Behavioral lateralization in the Florida manatee (Trichechus manatus latirostris). International Journal of Comparative Psychology, 29, 1-13.

Varma, S., Baskaran, N., and Sukumar, R. (2012). Field key for elephant population estimation and age and sex classification. Bangalore, Karnataka: Asian Nature Conservation Foundation, Innovation Centre, Indian Institute of Science and Centre for Ecological Sciences.

Vidya, T. N. C., Prasad, D., and Ghosh, A. (2014). Individual identification in Asian elephants. Gajah, 40, 3-17.

Wells, D. L. (2003). Lateralised behaviour in the domestic dog, Canis familiaris. Behavioural Processes, 61(1), 27-35. doi: 10.1016/S0376-6357(02)00161-4

Yasui, S., and Idani, G. I. (2016). Social significance of trunk use in captive Asian elephants. Ethology Ecology \& Evolution, 1-21. doi: 10.1080/03949370.2016.1179684 